\title{
Designing Policy Objects: Anti-Heroic Design
}

In Fisher, T. and Gamman, L. (2018). Tricky Design: The Ethics of Things. London: Bloomsbury, pp. 145-157

Lucy Kimbell

When in 1972 star designers Charles and Ray Eames were asked, "What are the boundaries of design?" - their answer, "What are the boundaries of problems?" (Eames Office 2016), demonstrated nicely the unboundedness and heroic, hubristic optimism associated with much designerly practice. The problems to which design is now being applied include organizational strategy, social issues such as caring for older people, public health issues such as obesity, humanitarian and development challenges, environmental issues such as food waste, and public service redesign. This is design as a field taking on issues facing communities and societies at different scales, moving beyond its entanglement with consumer culture and technological innovation towards actively reconstituting ways of living and being in ways that aim to be participatory, ethical and political (eg Armstrong et al 2014; Binder et al 2015; Koskinen and Hush 2016).

Against this background, this chapter considers government and public policy making as emerging sites for using design approaches, principles and practices. Using an auto-ethnographic account of my participation in a team of civil servants in the UK government and activism in a political party, I raise some of the ethical implications of this kind of designing. My account draws firstly on Agamben's (2009) revisiting of the concept of apparatus, highlighting the subjectification and desubjectification processes that accompany (co-)designing policy objects. It also invokes the Greek concept of métis (eg Singleton 2014) to consider opportunities to resist this subjectification of users, citizens and public servants within an apparatus such as public administration. In so doing I propose that anti-heroic design, characterized by a métic approach, has the potential to craftily sidestep, decentre or otherwise manoevure in relation to an apparatus.

\section{Design in and for public policy}

The last few years have seen a rapid expansion of examples for design for policy, alongside other kinds of experimentation in using "open" and digital data, behavioural science and foresight. As discussed by Bason (2014), design for public policy throws up questions for public servants and politicians about their expertise, organizational capabilities, and the logics through which they take action and engage with publics including voters and beneficiaries of public programmes. The international spread of "policy labs" in government entities such as central, regional or local government organisations, mostly in developed countries with stable democracies, has resulted in many more examples of applying design processes, methods, techniques and expertise to policy 
challenges with, as yet, unclear results (eg Bailey and Lloyd 2016; EU Policy Lab 2016).

As a socio-material configuration to be "designed", policy presents an interesting object of study for scholars of design. Public policy is a diffused social and political phenomenon with complex intersections with other domains including but not limited to politics, economics, social research and legal thought and practice. As the UK Civil Service describes it - in a handbook for civil servants who work directly with elected politicians who are ministers - policy making involves balancing "politics, evidence and delivery" (Civil Service Learning 2016). Policy making is presented as the active mediation between data and interpretation, in relation to participants and processes inside government departments, parliament, public bodies, civil society stakeholders and also involving where relevant those involved in implementation and evaluation. Within the field of policy studies, concepts such as policy "cycles" with phases of agenda-setting through to implementation and evaluation (eg Howlett 1991), or "streams" of activity (eg Kingdon 1995), have been developed to articulate the object and process of policy design. Reactions to instrumentalist, top-down or rationalist approaches have lead to growing interest in designerly approaches within designing policy (eg Howlett 2015).

As with the design of other kinds of socio-material thing, policy objects and processes are in flux. Factors shaping policy practice and thinking include: ongoing failures to find solutions to complex, dynamic issues; increasing datafication and digitisation of public administration; challenges to established means of representing issues and engaging stakeholders; the marketisation of public space; and the hold of neoliberal ideologies arguing for reshaping the role and size of state. These have resulted in new experiments, formats, devices, technologies and kinds of expertise in policy design. New policy development practices have co-emerged with developments in business and management. For example, the push to continuous experimentation in lean startup and agile software, funded by venture capital ever in search of novelty, has directly informed efforts to make government more agile (eg HM Government 2016a).

In short public policy design is a complex, dynamic context in which designerly practices, and sometimes professional designers, are now evident. The rapid proliferation of formats for bringing designer expertise into policy contexts poses questions about the nature of this emerging practice in public administration. To what extent can designerly optimism in coming up with new solutions to policy challenges engage with the often subtle, and highly politicized, cultural practices of public administration? How do new formats and techniques for policy making intersect with democratic structures and processes? To explore these questions, this chapter makes two moves to consider the opportunities for, and consequences of, public policy being an object for and in designerly practice.

\section{Apparatus and mētis}


Foucault's concept of apparatus has become a widely used analytical device to highlight the production and disciplining of human subjects within institutions. The apparatus is defined by Italian philosopher Giorgio Agamben in an essay on this concept (2009: 14) as "literally anything that has in some way the capacity to capture, orient, determine, intercept, model, control, or secure the gestures, behaviours, opinions, or discourses of living beings". His discussion highlights a difference between living beings and the apparatuses that capture and thereby seek to govern them. Agamben's examination of the apparatus begins by revisiting the early history of the Christian church, and describing the origins of a foundational split between humans (in the physical world) and god (in the spirit world). An apparatus is what separates us from our immediate environment and constructs subjectivities (how we are to be) in relation to their negation (how we are not to be). For Agamben, the only realistic strategy to resist this split is through profanation of the apparatus, saying: "Profanation is the counterapparatus that restores to common use what sacrifice as separated and divided" (2009: 19). For Agamben, profanation returns to ordinary life things that were previously considered "sacred", or apart.

Given the pervasiveness of apparatuses in contemporary life, Agamben notes an urgency "to bring to light the Ungovernable, which is the beginning and, at the same time, the vanishing point of every politics" (2009: 24). This highlights a key ethical challenge for design for and in public policy: whether design practice will serve to maintain the split between living beings and apparatuses - that result in the subjectification of citizens, users or beneficiaries of government policy, as well as public servants and politicians - or whether design will or can resist this split through profanation.

The second move draws on the ancient Greek concept of métis (Chia and Holt 2009; Cocker 2016; Mackay et al 2014; Singleton 2014). Often translated into English as "trickery" or "guile", mètis "stretches" (Nonaka et al 2014) the more familiar practical wisdom associated with the Greek term phronēsis. It offers an active, but unspectacular, form of engagement with the particulars of a situation or, as Singleton (2014: 14) puts it, not, "a scheme of domination but ... a manipulative gamble, morally complex but also extremely potent in its effects". Indirect strategic action shaped by mètis is "the ability to absorb contradiction, to display an array of character and a multiplicity of traits, none of which dominate and all of which can be brought into play without any inner fixation that blocks the renewal of one's self" (Chia and Holt 2009: 206).

Unlike phronēsis, mētis is morally neutral. Noting histories of distrust of "crafty" designers and their craft, Singleton points to how: "If mètis incorporates characteristics that are often considered attractive, like foresight, pragmatism and ingenuity, it can also imply insincerity, deceitfulness and manipulation" (2014: 129). From the perspective of organisation studies, Mackay et al (2014) use métis to describe situated resourcefulness in organisational contexts, enabling managers to do their work in contexts of ambiguity, conflict and complexity. In the arts, Cocker (2016: 244) uses the term to describe the work of artists Heath Bunting and Kayle Brandon as a "critical practice of willful unbelonging, a refusal to passively accept the increasingly limiting or restrictive 
criteria that denotes a particular kind of social belonging or citizenship, especially as perpetuated by and within contemporary neoliberalism".

Such explorations of mètis point towards organisational practices that are shifty and shifting, both enacting and responding to contradiction and uncertainty.

Being attentive to métis in the context of designing policy emphasizes the practical accommodations that enable new kinds of subjectivities to be imagined and brought into play in the work of public administration during dynamic change. Mètis has the potential for bringing the "sacred" back into common use in the way Agamben sketches out, by resisting an apparatus but without doing so dramatically or directly.

In what follows I use these two analytical moves to discuss auto-ethnographic vignettes from a year-long research fellowship in a team of civil servants (Kimbell 2015). Auto-ethnographic research focuses on the writing or performing self of the researcher and how she is constituted in relation to the social worlds she accounts for (eg Spry 2001; Russell 1999). For example, Spry (2001) has emphasised performativity and embodiment in research practices, through her affective and poetic intertwining of her "personal" stories with her "research" in a scholarly context in which performing is "academically heretical" (Spry 2001: 708). By presenting such accounts of my participation within government and local politics during my fellowship, I examine the opportunities and consequences of enacting a métic approach within public administration and politics. In writing this I have returned to field notes, photographs, emails and tweets from my participation in many meetings, workshops and events as well as interviews with civil servants in government departments ${ }^{1}$.

\section{Being in transition, being the apparatus}

In May 2015 a general election in the UK resulted in a majority of Conservative Members of Parliament (MPs) being voted in. This was unexpected as, even on the day of the vote, polls were predicting a win for the opposition Labour party. In the week after the election result, I spent several days among civil servants in central London, in the area known as Whitehall where many government departments are located. Over these days the new government took shape as the prime minister selected and announced his team of ministers. The previous government, formed in 2010, was a coalition of two parties, but this election had resulted in a majority for one party. One effect was that although some individual MPs might remain in post as ministers in the same role they had had before the election (such as the prime minister), the overall direction of policy making was now in the hands of a single party. For me, the election result was unwelcome news as I was a member of the Labour party and had been active in my local area knocking on doors, handing out leaflets and attending meetings ${ }^{2}$.

The second working day after the election, I was present on one floor of the building I had access to as part of my fellowship. I was curious to see what it would be like. My (lightly edited) notes read: 
I arrive at the Cabinet Office unfortunately without my pass so I have to wait downstairs until S comes to get me and I can get an unescorted oneday pass. Upstairs the tables are much tidier and it feels tense and excited ... We chat about the election night - sharing different reactions to the surprise result ... I ask who the new minister might be. P says she expects it to be Lord Maude ${ }^{3}$ but that 'they' (ie the Prime Minister and his team) might have to [appease a different wing of the party]... 'At least he was really interested in the Civil Service and the Cabinet Office.' A sense of busy-ness. ... I hear one senior civil servant say, 'The angle is the majority is paper thin.'

At this stage it was not clear for the people working in this government department if they will have a new minister - it's up to the Prime Minister to decide and there was as yet little news. As a researcher, I didn't receive the emails sent to civil servants but was able to pick up what was happening through what people were talking about. Over these days, many of the people around me were often on the phone or checking email, Twitter and news feeds. As ministerial appointments were announced, news spread and I overheard, or joined in with, discussions about the consequences for government departments and policy directions.

The third work day after the election, I was present at an informal meeting when several senior civil servants talked through what was happening, to make sense of the result and the implications going forward. One manager cautioned: "Don't think it's the same as three weeks ago. They have been through something cathartic and are coming in renewed". A few days later, I was present in the building when the new minister arrived on the floor I happened to be on. My notes read:

Some clapping round the corner ... I look up. I look at S for an explanation. He says it's the minister. We get up and go round the corner where people are still clapping. [Senior manager $\mathrm{N}$ ] is standing next to a man in jeans and a shirt - the new minister ... It feels a bit odd to be clapping a Tory minister less than a week after the election but I join in not to be conspicuous. The minister says, 'Thank you for the next five years... You'll work really hard...I look forward to working with [you] and taking all the credit'. Laughter. More clapping. We go back to our desks. S comes with me and translates for me: 'We need to do this to make the transition smoother. To build the trust. It didn't happen in 2010 with the incoming ministers and it was a real problem. But you see how we are - jump for the new minister.'

These few days of transition gave me embodied insights into the lived reality of civil servants as part of the apparatus of government. As I stood among a group of people clapping the new minister when he visited the building, I experienced the ambivalence of wanting certainty and a direction, but anxiety about what it might mean. I gained a sense of how civil servants are implicated in the apparatus of government, regardless of and possibly split from their own politics or beliefs. A métic lens suggests such behavior is part of the craft of public 
service, requiring resourceful pragmatism in order to maintain the split between public servants and their worlds beyond their professional obligations.

Through temporarily being part of this apparatus and separated from my own commitments, I experienced something of this split. But an unconscious slip-up revealed my own resistance to it. On the first day after the election I went to the office without my access pass - an easy mistake to make, but a rare one. This suggested how unconsciously I was marking out my role and accountabilities as different to those of the public servants. As a researcher my work is publically funded and shaped by academic standards and guidelines. Like civil servants, I am expected not to enact party politics within my work. But within my free time I have been experimenting in bringing designerly approaches into local party politics, which produces insights into the subjectivities constructed through the UK's democratic apparatus.

\section{Opening up participation, manifesting the ungovernable}

In July 2015 I co-organized a public meeting to bring people together to find out more about food poverty in my local area, and what can be done about it. All of the organisers were members of a local branch of the Labour Party, but we wanted the event to attract other local residents, not just members. This event was the second in a series of "open meetings" through which we aimed to open up participation in party politics. Our objectives in organising this meeting were that: more people knew about existing schemes and organisations active in relation to UK food poverty resulting in more donations and new users and volunteers; everyone in the room had the opportunity to generate and share ideas about how to address food poverty; food was gathered for the local voluntary foodbank; and the Labour Party was involved in doing something practical in the area. Ahead of the meeting we designed, produced, handed out and delivered flyers advertising the event, as well using social media. We found and briefed speakers, booked the venue and attended to the other practicalities of such events.

Held on a Saturday afternoon in a community centre, the event was attended by 35 people, the majority of whom were party members. Many of the meetings organised by the party in the area adopt a format of a speaker talking in a plenary session to an audience, with opportunities for questions. The format for the open meeting combined hearing from people with direct knowledge of the issue with individuals talking in small groups. As organizers, we believed this opened up more opportunities for people to take part, by sharing their own perspectives, experiences and ideas.

After hearing from speakers from a local food bank, a supermarket that collects food donations, and from an elected councillor, participants were invited to talk at tables in small groups to explore the issues in more depth. For some participants, this shift in register, while welcome, lead to their checking in several times with us, the organizers: "What do you want us to do?" But as individuals in the small groups grasped the format and found their voices, the energy in the room from people talking and listening to one another could heard 
and felt. Further, the structure we proposed of first discussing the issue, and then coming up with potential solutions, and distinguishing between sites and scales of action (such as campaigning, policy, local government, and volunteering) helped distinguish different responses to UK food poverty.

There was, however, one interesting challenge to the format. This came from one of the participants who wanted to share her experience of (food) poverty. For the most part, this participant ignored the invitations to follow the structure for the meeting. Her spoken and embodied interventions were focused on telling her own story, from when she was younger and did not have enough food to eat. She wanted and needed to be heard; this event had seemed to offer the promise of this.

On the one hand, this participant was doing what we had asked - bringing into view the experiences of people in the UK who did not have enough food to eat to understand the conditions, drivers, and consequences of food poverty. On the other, she was resisting the rules of engagement of the open meeting, by not talking to the people she was sitting next to, and ignoring the structured activities including invitations to generate and share ideas. Our format wanted to tidy away - perhaps colonise? - her memories of suffering, anger and sense of injustice, and channel it into the production of "ideas".

This woman's responses and the nature of her stories exceeded the format and process of the meeting. Instead of the cordial rationality we, the organizers, required, her response resisted the modes of knowing and being built into our design. The apparatus of our open meeting required particular kinds of disciplined participant for it to work. The affective excess produced by this participant constituted, in Agamben's terms, a profanation of the apparatus. Bringing this participant's feelings, agency and purposes into the workshop revealed something of the "ungovernable" which was at once thrilling and frightening to me, as one of the organisers. Individual resistance such as this can disrupt the workings of an apparatus in productive ways. But to what extent can organisational practices, such as professional design, enact a collective profanation of an apparatus? Returning to the context of public administration, I explore this by discussing findings from my participation in a team within the UK government (Kimbell 2015; Kimbell 2016).

\section{Calculating impact, exceeding professional practice}

Set up in 2014 as part of efforts to change the work practices of the UK Civil Service (HM Government 2012), Policy Lab is a team consisting of a small number of public servants within central government working with policy officials and others in government departments, sometimes supported by specialist consultancies. As described on its blog: "Policy Lab is bringing new policy tools and techniques to the UK Government. We are a creative space where policy teams can develop the knowledge and skills to develop policy in a more open, data-driven, digital and user-centred way.... Policy Lab support is best suited to tackling intractable, complex, systemic policy problems that require fresh thinking that can lead to potentially transformative solutions" 
(Policy Lab 2017a). The team includes people with backgrounds in policy, design, ethnography, digital and futures. Policy Lab co-exists with other more established players inside the UK government including the award-winning Government Digital Service (HM Government 2016a, 2016b), which advocates for designing for user needs and using prototyping in the design of digital public services. Internationally, there is a flourishing ecosystem of people exploring and advocating "policy innovation" with associated networks, events and research (eg EU Policy Lab 2016).

Throughout my research, there was an enduring challenge faced by Policy Lab: how to account for its practices and assess its impact in ways that worked for stakeholders, especially sponsors inside the Civil Service, so it could continue to exist, or possibly grow. The terms of how to make this calculation were not clear. The team were tasked with helping build a culture of open policy making including getting wider input into defining problems and generating solutions, and by testing policy solutions before they are implemented, to lead to more effective and successful policy making (HM Government 2012). Within a government committed to deficit reduction (HM Treasury 2015), much of the contemporary discussion about "solutions" was shaped by a political requirement to reduce spending. So on the one hand, the team were part of the apparatus, which requires public servants to be split from their own perspectives, beliefs and commitments, to generate and deliver such solutions. But on the other, innovative practices might go beyond current framings or lead to results that did not fit in existing ways of doing things.

As a new team, with funding initially for one year, headcount equivalent to 2.4 people and a relatively small budget in government terms, Policy Lab had limited resources. Notes from discussions I took part in highlight the ongoing challenge of understanding and describing the frames within which Policy Lab's activities could be assessed. Some of the people cited in these discussions were elected politicians or senior managers with interest in or responsibility for the team's activities. Alongside these conversations, there were many activities through which the team monitored and evaluated its work more formally, for example in regular reports to and meetings with senior colleagues and via an independent assessment by a consultancy.

You could frame Lab in lots of different ways ... efficiency savings, outcomes. T says 'I want to show the monetary benefit' but then says 'I don't believe it'.

T's agenda for [a senior civil servant] is 'Where's the $£ 10$ billion solution not the $£ 500,000$ solution?' The projects we pick have to be right on the one hand ... something captivating, compelling, to demonstrate what others have not been able to do... What can we do in the system that people could point to as an emerging [organisational] technology like $3 \mathrm{~d}$ printing? 
One aspect of this calculation, to which the team returned regularly, was Policy Lab's symbolic value. On occasion, this was seen as having more persuasive power than the team's ability to effect improvements and savings.

Does a lab serve a symbolic role or does it have to deliver impact?

Lab is distinctive ... it's in the global club of labs... its symbolic value is as a lab in addition to its practical ability to deliver change.

Frequent use of the term "experimental" and the name Policy "Lab" itself emphasised the provisional, uncertain nature of this new way of working inside government, even if the team drew on established ways of working inside business and social innovation settings. Such experimentality contrasted with that of another, highly visible and much larger team built up from 2010 from within the UK Civil Service, the Behavioural Insights Team (BIT). BIT's work is closely associated with social science research - social psychology and behavioural economics - and with an experimental technique - randomised control trials (RCTs) (eg Haynes et al 2013). Through testing policy interventions that emphasise analytical rigour in the tradition of the experimental sciences, BIT asserts a knowledge base and a methodology. In contrast, Policy Lab's experimentation is more fluid, emphasises creative engagement with a problem, is pluralist in its intellectual lineages, and co-emerges with its context.

We tried out 12 tools and the approach associated with them. By trying them out we gain licence to try out more things.

We are trying to fine-tune what works in this space.

A brief account of these "tools" in use in one setting brings into view how such experimentation works in practice ${ }^{4}$. It draws out the ways that Policy Lab carries out this fine-tuning in response to a matter at hand, rather than in relation to a fixed, well-established framing, and opens up discussion about the nature of policy work. In so doing, I suggest this allows participants to manoeuvre in relation to dominant assumptions about policy making practice and the identities associated with public service, resisting the apparatus of which civil servants form a part by connecting them to their purposes, their emotions and to their wider worlds.

For example, in many workshops run by Policy Lab, an opening move is to engage participants in expressing hopes and fears for their shared project or relating to the policy issue at stake. Typically, a member of the Policy Lab team distributes on the floor or a table a selection of postcards, each with a printed image and an empty space below. Participants are invited to pick one card to express their fear regarding the topic at hand, and write a few words on the card. They then share what they have written with one another. This is then repeated for the group to describe their hopes for the topic or project.

During an hour-long workshop I attended, the policy officials who participated spent a few minutes describing their fears for what policy work might look like 
in central government. A picture of a clock was a chosen to represent the fear of getting behind. A picture of wires was selected to communicate feeling lonely and disconnected. A picture of sky said: "Too much blue sky, not enough delivery." When discussing their hopes, participants introduced other concepts in response to the postcards available. A picture of binoculars represented: "Short and long range vision". A pair of shoes were the hope of "buy in". A picture of a London department store was chosen to communicate "world class ideas" and being "symbolic internationally". In only a few minutes, this activity connected participants to their own feelings about their work by using a small set of images to elicit responses, privileging subjective experience over evidence and analysis.

This exercise was followed by three more activities. The first was constructing a "persona" of a civil servant involved in policy making, produced by participants sketching or writing notes in response to characteristics called out by the facilitator. This was followed by each participant writing down a "challenge" faced by policy officials inside government, which they then presented to one another. Finally, participants worked in small teams to come up with, sketch, share and discuss solutions to these challenges. One such solution, for example, visualised an iterative policy making cycle with multiple inputs at many points in time. Outcomes of this intense, fast-paced hour included not just insights into current practices, barriers to change, and ideas for how the policy making process might work, but also practical, creative engagement with these topics and a sense of open dialogue between participants.

Through taster workshops such as this, and longer demonstration projects working closely with civil servants on a specific policy issue, Policy Lab invited participants to engage materially and discursively in reconstituting the issue of how policy making could be practiced. Emphasising the visual and performative, rather than the numeric or textual as is more common among policy officials, such activities sidestep the conventional ways of knowing within public administration. The team's practice offers a series of uncertainties in which policy officials were constructed as active participants in exploring issues and imagining collective futures. Much of this was accompanied by self-deprecating, often humorous facilitation and informality, while carefully following Civil Service conventions such as referring to ministers, senior civil servants, and current policy agendas to legitimise activity. Through its open-ended, generative activities, the team enabled participants to connect with what is often kept apart from their professional practice - their subjective sense of purpose, creating a context in which they can "experiment" by questioning assumptions about a policy issue, its ecosystem and potential solutions. Policy Lab generates and holds open a space where "next practice" - a term frequently used by the team can be co-imagined. This emphasis on subjectivity and not-knowing - or not-yetknowing - enough about a policy issue or what a solution might be, can be seen as a profanation of the apparatus of public administration.

Using the lens of a mètic design approach, what comes into view is resistance to presenting an authoritative account of civil service practice. Insights and solutions may be generated by Policy Lab through ethnographic research and co- 
design. But the team's efforts are also directed towards experimentally coproducing an organisational capacity enabling civil servants to reconnect with their purposes and subjectivities to they can reimagine policy making and collectively explore problems and solutions. Unassuming but provocative, contextual and specific rather than generalisable, Policy Lab's designerly practices inside government hint at an anti-heroic experimentation and partial, ever provisional solutions. By absorbing contradiction and being resourceful, Policy Lab has been able to shift and respond to changes in its environment, sidestepping dominant framings to the extent that the team continues to exist with licence to probe future policy making practices.

\section{Conclusion}

Earlier I noted the increasing visibility of designerly expertise within policy contexts, and questioned to what extent it can resist being part of an apparatus and the processes of subjectification and desubjectification that accompany it. Illuminated by the accounts presented above, I now consider the extent to which the optimism associated with design practice in coming up with new solutions to policy challenges can be productive, given the politicised cultural practices of government bodies. Two possible directions for professional design practice emerge in relation to the design of socio-material policy objects.

One option is for design to be enfolded within the work of public administration. Here, designing is a new competence for policy officials to master. This heroic design is on the side of purposefulness and strategic action to address public policy challenges, adding a human-centred perspective and insights into end user experiences. However it can serve to maintain the split between an apparatus and living beings and is unavoidably implicated in processes of subjectification and desubjectification. Its activities result in producing good or bad citizens, workshop participants, users, beneficiaries or public servants, and indeed policies, which maintain the split that separates living beings from their environment, and give some actors more agency or legitimacy and others less. Such a competence competes with other heroic accounts that produce solutions in accordance with modernist science, and evidence about what works, but fail to reimagine what "working" might mean.

The second - perhaps more troubling - option is to develop a mètic design practice, emphasising the improvisational and the circuitous. This anti-heroic design for policy has the potential to resist the apparatus and its associated subjectification and desubjectification processes. By profaning the apparatus, anti-heroic design highlights the ungovernable, the unfolding of which may produce new kinds of subjectivities and may result in new ways of living, working, knowing or being. This anti-heroic design eschews the calculability associated with much contemporary design practice that demonstrates "value" or "impact" or reflects on its "role". Instead, it poses the question of its contribution as something to be explored and re-made.

Given recent political developments that have resulted in unexpected leaders and unanticipated decisions through democratic processes, this anti-heroic 
design is worth exploring further. Perhaps instead of "design to the rescue" emphasising a heroic, active engagement with government, other aspects of designerly practice can be mobilised as Singleton (2014) argues. Recognising the potential for profanation enabled by a mètic approach positions design as antiheroic, through cunning, intelligence and unspectacular practical engagement with the particulars of the situation. Acknowledging and enabling this capacity has the potential to produce less alarming ungovernables.

\section{Acknowledgements}

This research was funded by a fellowship from the Arts and Humanities Research Council. Thanks to Jamie Brassett for introducing me to Agamben's essay and for suggestions that improved this chapter, and to Jamie, Guy Julier, Noortje Marres and Jocelyn Bailey for ongoing discussions about design, policy and the social.

Agamben, G., 2009. What is an apparatus? And Other Essays. Stanford: Stanford University Press.

Armstrong, L., Bailey, J., Julier, G., and Kimbell, L., 2014. Social design futures: Social design research and the AHRC. Brighton: University of Brighton.

Bailey, J. and Lloyd, P. 2016. The introduction of design to policymaking: Policy Lab and the UK Government. In: Proceedings of DRS2016: Design Research Society Conference, Brighton, UK, 27-30 June 2016.

Bason, C., (ed), 2014. Design for policy. Abingdon: Routledge

Binder, T., Brandt, E., Ehn, P., and Halse, J., 2015. Democratic design experiments: between parliament and laboratory. CoDesign, 11(3-4), 152-165.

Burton, P., 2006. Modernising the policy process: Making policy research more significant? Policy Studies, 27(3), 173-195.

Chia, R., and Holt, R., 2009. Strategy without design: the silent efficacy of indirect action. Cambridge: Cambridge University Press

Civil Service Learning. 2015. Working with ministers. Available at:

https://civilservicelearning.civilservice.gov.uk/sites/default/files/working_with _ministers_-_a_handbook__final.pdf [Accessed 6 July 2016].

Cocker, E., (2016). Looking for loopholes: the cartography of escape. In: Bishop, K.E. (ed), Cartographies of exile: A new spatial literacy. Abingdon: Routledge.

Eames Office. Available at: http://www.eamesoffice.com/the-work/design-q-atext/. [Accessed 11 December 2016].

EU Policy Lab, 2016. Lab connections. Available at: http://blogs.ec.europa.eu/eupolicylab/lab-connections/. [Accessed 11

December 2016].

Fuerth, L., 2009. Foresight and anticipatory governance. Foresight 11(4): 14-32.

HM Government, 2012. The Civil Service reform plan. Available at: https://www.gov.uk/government/publications/civil-service-reform-plan [Accessed 11 March 2017]. 
HM Government, 2013. Civil service conduct and guidance. Available at: https://www.gov.uk/government/collections/civil-service-conduct-andguidance [Accessed 11 January 2017].

HM Government, 2016a. Gov.uk service manual. Agile methods: An introduction. Available at: https://www.gov.uk/service-manual/agile-delivery/agilemethodologies [Accessed 11 December 2016].

HM Government. 2016b. Start by learning user needs. Published 4 April 2016. https://www.gov.uk/service-manual/user-research/start-by-learning-userneeds

HM Treasury, 2015. 2010 to 2015 government policy: Deficit reduction.

Available at: https://www.gov.uk/government/publications/2010-to-2015government-policy-deficit-reduction [Accessed 11 March 2017].

Haynes, L., Service, O., Goldacre, B. and Torgerson, D., (2013). Test, learn, adapt: Developing public policy with randomised controlled trials. London: Cabinet Office. Howlett, M., 1991. Policy instruments, policy styles and policy implementation, Policy Studies Journal, 19 (2), 1-21.

Howlett, M., 2015. From tools to toolkits in policy design studies: the new design orientation towards policy formulation research. Policy and Politics, 43, (2), 291311.

Kimbell, L., 2015. Applying design approaches to policy making: Discovering Policy Lab. Brighton: University of Brighton.

Kimbell, L., 2016. Design in the time of policy problems. In: Proceedings of DRS2016: Design Research Society Conference, Brighton, UK, 27-30 June 2016.

Kingdon, J. W., 1995. Agendas, alternatives and public policies. 2nd ed. New York: Harper Collins.

Koskinen, I., and Hush, G., 2016. Utopian, molecular and sociological social design. International Journal of Design, 10(1), 65-71.

Mackay, D., Zundel, M. and Alkirwi, M., 2014. Exploring the practical wisdom of metis for management learning. Management Learning, 45, (4), 418-436.

Nonaka, T., Chia, R., Holt, R. and Peltokorpi, V., 2014. Wisdom, management and organization. Management Learning. 45, (4), 365-376.

Policy Lab, 2017a. About Policy Lab. Available at:

https://openpolicy.blog.gov.uk/about/ [Accessed 11 January 2017].

Policy Lab, 2017b. Method bank and toolkit. Available at

https://www.slideshare.net/Openpolicymaking/methodbank-and-toolkit-fordesign-in-government [Accessed 11 January 2017].

Russell, C., 1999. Experimental ethnography: The work of film in the age of video. Durham: Duke University Press.

Singleton, B., 2012. On craft and being crafty: Human behaviour as the object of design. Unpublished PhD Thesis. University of Northumbria.

Spry, T., 2001. Performing autoethnography: An embodied methodological praxis. Qualitative Inquiry, 7(6), 706-732.

\footnotetext{
${ }^{1}$ Details have been changed to retain anonymity, such as names, genders, roles and locations, and in relation to confidential material. Given working in an open plan office and my access to workshops, meetings and interviews, the civil servants who I describe here may work in several government departments.
} 
2 Some civil servants I knew were supporters or members of several different political parties. Their engagement with politics is shaped by clear guidance, in the form of the Civil Service Code, and cultural practices which aim to separate their professional obligations and personal views (HM Government 2013).

${ }^{3}$ Francis Maude was a Conservative Member of Parliament and minister who was actively involved in leading the government's Civil Service reform and open government agendas and developing the Government Digital Service.

${ }^{4}$ For more on Policy Lab's design tools adapted for policy making see Policy Lab (2017b). 